40 
Operator Theory: Advances and

Applications

Vol. 158

Editor:

I. Gohberg

Editorial Office:

School of Mathematical

Sciences

Tel Aviv University

Ramat Aviv, Israel

Editorial Board:

D. Alpay (Beer-Sheva)

J. Arazy (Haifa)

A. Atzmon (Tel Aviv)

J. A. Ball (Blacksburg)

A. Ben-Artzi (Tel Aviv)

$\mathrm{H}$. Bercovici (Bloomington)

A. Böttcher (Chemnitz)

K. Clancey (Athens, USA)

L. A. Coburn (Buffalo)

K. R. Davidson (Waterloo, Ontario)

R. G. Douglas (College Station)

A. Dijksma (Groningen)

H. Dym (Rehovot)

P. A. Fuhrmann (Beer Sheva)

B. Gramsch (Mainz)

G. Heinig (Chemnitz)

J. A. Helton (La Jolla)

M. A. Kaashoek (Amsterdam)
H. G. Kaper (Argonne)

S. T. Kuroda (Tokyo)

P. Lancaster (Calgary)

L. E. Lerer (Haifa)

B. Mityagin (Columbus)

V. V. Peller (Manhattan, Kansas)

L. Rodman (Williamsburg)

J. Rovnyak (Charlottesville)

D. E. Sarason (Berkeley)

I. M. Spitkovsky (Williamsburg)

S. Treil (Providence)

H. Upmeier (Marburg)

S. M. Verduyn Lunel (Leiden)

D. Voiculescu (Berkeley)

H. Widom (Santa Cruz)

D. Xia (Nashville)

D. Yafaev (Rennes)

Honorary and Advisory

Editorial Board:

C. Foias (Bloomington)

P. R. Halmos (Santa Clara)

T. Kailath (Stanford)

P. D. Lax (New York)

M. S. Livsic (Beer Sheva) 


\section{Selected Topics in Complex Analysis}

\section{The S. Ya. Khavinson Memorial Volume}

V. Ya. Eiderman

M. V. Samokhin

Editors 
Editors:

Vladimir Ya. Eiderman

Mikhail V. Samokhin

Moscow State Civil Engineering University

Department of Higher Mathematics

Yaroslavskoye shosse, 26

129337 Moscow

Russia

e-mail: eiderman@orc.ru

msamokh@mgsu.ru

2000 Mathematics Subject Classification 01-02, 01-06, 01A70, 30-06, 31-06, 32-06, 47-06

A CIP catalogue record for this book is available from the Library of Congress, Washington D.C., USA

Bibliographic information published by Die Deutsche Bibliothek

Die Deutsche Bibliothek lists this publication in the Deutsche Nationalbibliografie; detailed bibliographic data is available in the Internet at <http://dnb.ddb.de $>$.

\section{ISBN 3-7643-7251-6 Birkhäuser Verlag, Basel - Boston - Berlin}

This work is subject to copyright. All rights are reserved, whether the whole or part of the material is concerned, specifically the rights of translation, reprinting, re-use of illustrations, recitation, broadcasting, reproduction on microfilms or in other ways, and storage in data banks. For any kind of use permission of the copyright owner must be obtained.

(C) 2005 Birkhäuser Verlag, P.O. Box 133, CH-4010 Basel, Switzerland

Part of Springer Science+Business Media

Printed on acid-free paper produced from chlorine-free pulp. TCF $\infty$

Cover design: Heinz Hiltbrunner, Basel

Printed in Germany

ISBN 10: 3-7643-7251-6

ISBN 13: 978-3-7643-7251-4 
Dedicated to the memory of

Semyon Yakovlevich Khavinson 


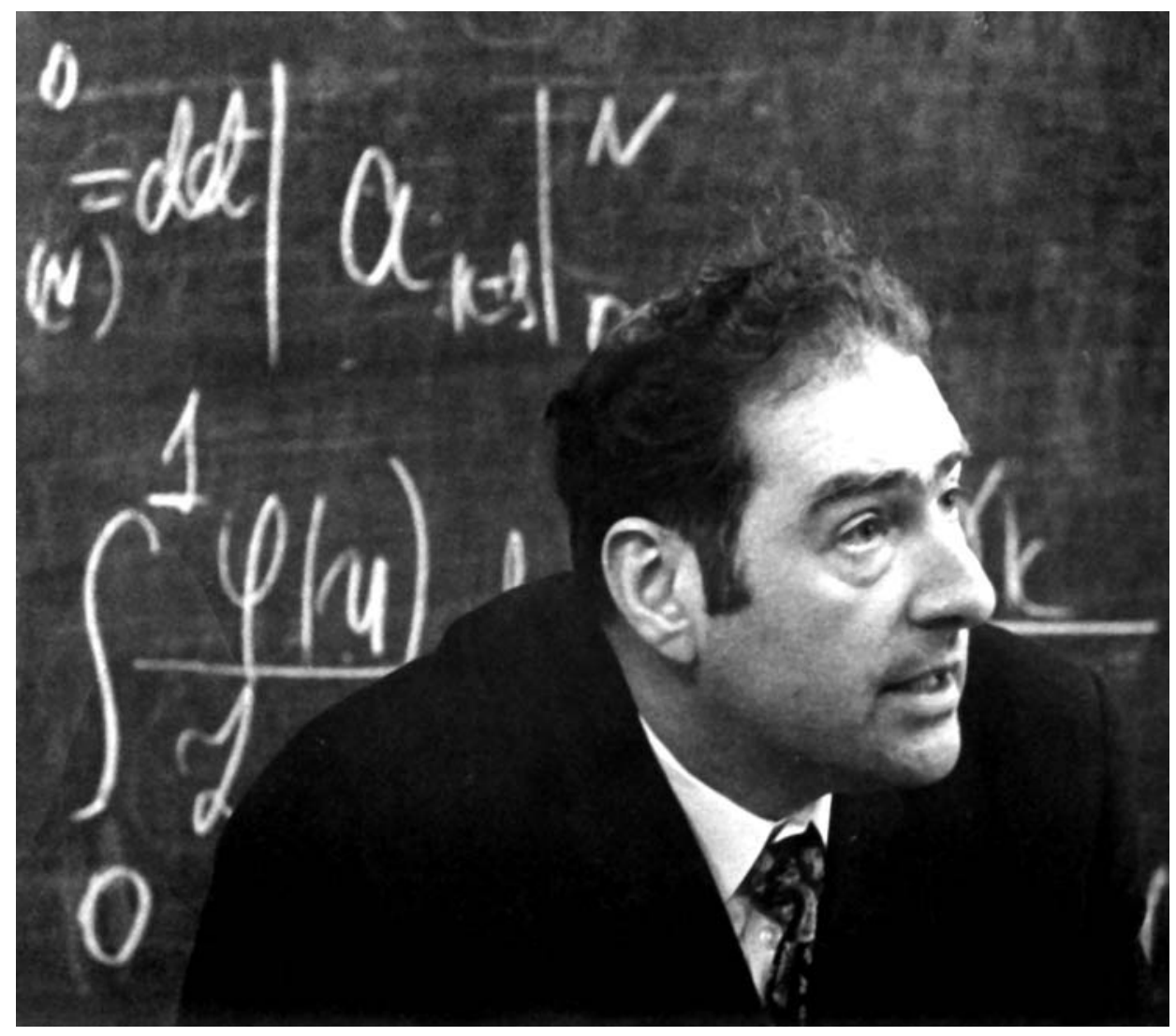

Semyon Yakovlevich Khavinson

1927-2003 


\section{Contents}

Semyon Yakovlevich Khavinson (May 17, 1927 - January 30, 2003) ...... 1

S.Ya. Khavinson: Bibliography $\ldots \ldots \ldots \ldots \ldots \ldots \ldots \ldots \ldots \ldots \ldots \ldots . \ldots \ldots$

S.Ya. Khavinson: Photos ................................. 33

S.Ya. Khavinson and T.S. Kuzina

The Structural Formulae for Extremal Functions

in Hardy Classes on Finite Riemann Surfaces .................. 37

D. Aharonov, C. Bénéteau, D. Khavinson and H.S. Shapiro

Extremal Problems for Nonvanishing Functions

in Bergman Spaces ................................... 59

L. Aizenberg

Generalization of Carathéodory's Inequality and

the Bohr Radius for Multidimensional Power Series ............. 87

J.M. Anderson

Remarks on the Value Distribution of Meromorphic Functions ...... 95

J.T. Anderson and J. Wermer

Approximation Problems on the Unit Sphere in $\mathbf{C}^{2} \ldots \ldots \ldots \ldots \ldots . .101$

J.J. Carmona and K.Yu. Fedorovskiy

Conformal Maps and Uniform Approximation

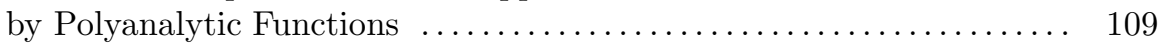

V.Ya. Eiderman

Capacities of Generalized Cantor Sets ....................... 131

A.M. Jerbashian

On $A_{\omega, \gamma}^{p}$ Spaces in the Half-Plane $\ldots \ldots \ldots \ldots \ldots \ldots \ldots \ldots \ldots \ldots \ldots \ldots \ldots \ldots$

M. Melnikov and X. Tolsa

Estimate of the Cauchy Integral over Ahlfors Regular Curves . ..... 159

Xuecheng Pang, S. Nevo and L. Zalcman

Quasinormal Families of Meromorphic Functions II $\ldots \ldots \ldots \ldots \ldots \ldots .177$

W.T. Ross

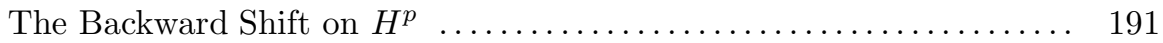

V.S. Videnskii

On Some Classes of $q$-parametric Positive linear Operators ........ 213 